This is an electronic reprint of the original article. This reprint may differ from the original in pagination and typographic detail.

\author{
Author(s): Hakulinen, Christian; Elovainio, Marko; Pulkki-Råback, Laura; Böckerman, Petri; \\ Viinikainen, Jutta; Pehkonen, Jaakko; Raitakari, Olli T.; Keltikangas-Järvinen, Liisa; \\ Hintsanen, Mirka
}

Title: Depressive symptoms and long-term income : The Young Finns Study

Year: $\quad 2016$

Version:

Please cite the original version:

Hakulinen, C., Elovainio, M., Pulkki-Råback, L., Böckerman, P., Viinikainen, J., Pehkonen, J., Raitakari, O. T., Keltikangas-Järvinen, L., \& Hintsanen, M. (2016). Depressive symptoms and long-term income : The Young Finns Study. Journal of Affective Disorders, 204, 120-123. https://doi.org/10.1016/j.jad.2016.06.028

All material supplied via JYX is protected by copyright and other intellectual property rights, and duplication or sale of all or part of any of the repository collections is not permitted, except that material may be duplicated by you for your research use or educational purposes in electronic or print form. You must obtain permission for any other use. Electronic or print copies may not be offered, whether for sale or otherwise to anyone who is not an authorised user. 


\section{Author's Accepted Manuscript}

Depressive symptoms and long-term income: The Young Finns Study

Christian Hakulinen, Marko Elovainio, Laura Pulkki-Råback, Petri Böckerman, Jutta Viinikainen, Jaakko Pehkonen, Olli T Raitakari, Liisa Keltikangas-Järvinen, Mirka Hintsanen

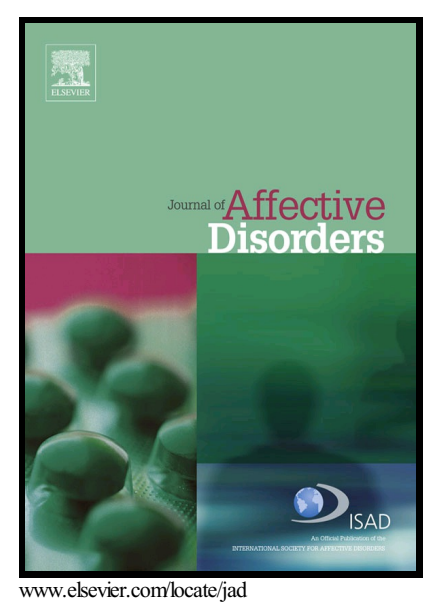

PII: $\quad$ S0165-0327(16)30378-0

DOI: $\quad$ http://dx.doi.org/10.1016/j.jad.2016.06.028

Reference: JAD8318

To appear in: Journal of Affective Disorders

Received date: 8 March 2016

Revised date: 6 June 2016

Accepted date: 11 June 2016

Cite this article as: Christian Hakulinen, Marko Elovainio, Laura Pulkki-Råback Petri Böckerman, Jutta Viinikainen, Jaakko Pehkonen, Olli T Raitakari, Liis‘ Keltikangas-Järvinen and Mirka Hintsanen, Depressive symptoms and long-terr income: The Young Finns Study, Journal of Affective Disorders http://dx.doi.org/10.1016/j.jad.2016.06.028

This is a PDF file of an unedited manuscript that has been accepted fo publication. As a service to our customers we are providing this early version o the manuscript. The manuscript will undergo copyediting, typesetting, an review of the resulting galley proof before it is published in its final citable form Please note that during the production process errors may be discovered whic could affect the content, and all legal disclaimers that apply to the journal pertain 
TITLE: Depressive symptoms and long-term income: The Young Finns Study

Christian Hakulinen*

Institute of Behavioural Sciences, University of Helsinki, Finland Marko Elovainio

Institute of Behavioural Sciences, University of Helsinki, Finland

National Institute for Health and Welfare, Helsinki, Finland

Laura Pulkki-Råback

Helsinki Collegium for Advanced Studies, University of Helsinki, Finland

Institute of Behavioural Sciences, University of Helsinki, Finland

Petri Böckerman

Turku School of Economics, Finland

Labour Institute for Economic Research, Helsinki, Finland

\author{
IZA, Bonn \\ Jutta Viinikainen
}

Jyväskylä University School of Business and Economics, University of Jyväskylä, Finland Jaakko Pehkonen

Jyväskylä University School of Business and Economics, University of Jyväskylä, Finland

Olli T Raitakari

Research Centre of Applied and Preventive Cardiovascular Medicine, University of Turku, Finland

Department of Clinical Physiology and Nuclear Medicine, Turku University Hospital, Finland Liisa Keltikangas-Järvinen

Institute of Behavioural Sciences, University of Helsinki, Finland

\title{
Mirka Hintsanen
}

Unit of Psychology, Faculty of Education, University of Oulu, Finland.

*Corresponding author: Christian Hakulinen. Institute of Behavioural Sciences, University of Helsinki, P.O. Box 9, 00014 University of Helsinki, Finland. E-mail:

christian.hakulinen@helsinki.fi, Tel.: +358 504482041.

Word count: 1702 words in the text; 220 words in the abstract; 2 tables 
Background: Higher depressive symptoms have been associated with lower future income. However, studies examining this issue have had limited follow-up times and have used selfreported measures of income. Also, possible confounders or mediators have not been accounted. Methods: 971 women and 738 men were selected from the ongoing prospective Young Finns Study (YFS) that began in 1980. Depressive symptoms were measured in 1992 when participants were from 15 to 30 years old. Information on annual income and earnings from 1993 to 2010 were obtained from the Finnish Longitudinal Employer-Employee Data (FLEED) of Statistics Finland and linked to the YFS.

Results: Higher depressive symptoms were associated with lower future income and earnings. For men, the associations were robust for controlling childhood parental socioeconomic status, history of unemployment, and adulthood health behavior, but attenuated circa $35 \%$ when three major temperament traits were taken into account. For women, similar pattern was found, however, in the models adjusted for temperament traits the associations did not remain statistically significant. The association between depressive symptoms and earnings was three times stronger for men than women.

Limitations: Previous depressive episodes could have influenced on some participants' economic and educational choices.

Conclusions: Higher depressive symptoms in adolescence and early adulthood lead to significant future losses of total income and earnings, and this association is particularly strong for men.

Keywords: Depressive symptoms; income; earnings; prospective; longitudinal INTRODUCTION 
Depressive disorders are a leading cause of global disease burden (Ferrari et al., 2013). Studies have repeatedly shown that depressive symptoms are more common among individuals in lower socioeconomic groups (Lorant, 2003). There are also some studies that have examined the effect of depressive symptoms on income later in life (Elovainio et al., 2012; Whooley et al., 2002; Zimmerman and Katon, 2005). Although these studies have shown that higher depressive symptoms or depressive disorder are associated with lower future income (Elovainio et al., 2012; Whooley et al., 2002; Zimmerman and Katon, 2005), the possible confounders or mediators that explain this association remain unaccounted. In addition, previous studies have had limited follow-up times and they have typically used single point self-reported measures of total income, which is prone to reporting biases and measurement error. Thus, average income over a longer period is a more reliable measure of economic prospects.

In this study we examined the prospective association between depressive symptoms with future income and earnings using a sample of Finnish adolescents and young adults. In addition, we examined whether childhood parental socioeconomic status (SES), participants history of unemployment, adulthood health behaviors, and adulthood temperament traits explain the examined associations. Annual measures of total income and earnings were obtained from comprehensive register data of Statistics Finland and they covered over 17 years of follow-up. Previous study based on the same data showed that higher depressive symptoms were associated with self-reported income at one measurement point (Elovainio et al., 2012). Thus, we hypothesized that similar association would be also found with register-based long-term income measures.

\section{METHODS}


Depressive symptoms and income

\section{Participants}

Participants were selected from the ongoing Young Finns Study (YFS) that began in 1980 (Raitakari et al., 2008). The original sample included 3596 children and adolescents (aged 3, 6, $9,12,15$, and 18 in 1980) that were randomly selected from the population register of areas near five Finnish university cities and their vicinity. Up to date, several follow-up data collections have been conducted. Written informed consent was obtained from participants who were at least 9 years old and from the parents of younger participants. Research plan and data collection procedures were accepted by the participating universities review boards, and data collection was conducted according to WHO standards as well as the Helsinki Declaration.

In total, 1709 participants had complete data available from the study baseline in 1980 and from the follow-up in year 1992 when depressive symptoms were measured. To obtain comprehensive register-based information on participants' earnings, YFS was linked to the Finnish Longitudinal Employer-Employee Data (FLEED) of Statistics Finland using social security numbers. Details of the FLEED have been reported elsewhere (Pehkonen et al., 2015), but in short, FLEED records periods of employment and gathers data on income and annual earnings from the state-run pension and tax registers that cover all legal employment contracts. For the current study, total income and earnings were obtained from 1993 to 2010.

\section{Measures}

Parental SES in 1980 was assessed using years of education of mother and father, and the annual income of the household (measured on an eight-point scale). To combine two different measures, the mean of parents' years of education was calculated and then standardized. Income was also standardized and then added to the standardized years of education resulting a composite 
measure of SES (Pulkki et al., 2003). Participants' own education was obtained from FLEED where information whether participant had obtained tertiary education by year 2010 was available.

Depressive symptoms were assessed using a modified version of the Beck Depression Inventory (BDI) (Katainen et al., 1999), where the second mildest symptom statement of each item of the original BDI was answered using a five-point scale ranging from $1=$ 'not at all' to $5=$ 'very much'. Average of these items were taken, and thus the theoretical range of the scale is from 1 to 5. Modified BDI has been shown to be a reliable measure that provides more information on less severe depression cases than the BDI-II (Rosenström et al., 2012). Three major temperament traits, i.e., negative emotionality, activity and sociability, were measured using 27-item EAS-questionnaire that has been shown to have good validity (Elovainio et al., 2014). History of unemployment from 1986 to 1992 (yes/no) and smoking (yes/no) were selfreported. Alcohol consumption was calculated based on consumption of beer, strong beer, wine, cider and spirits. High alcohol consumption was defined as either (1) daily consumption of any alcohol beverages or (2) consumption of any two types of alcohol beverages (e.g., beer and wine) during the week.

Income was measured as the logarithm of the average of annual taxable income over the period of 1993-2010. Taxable income is a broad income measure, which includes annual wage and salary earnings, self-employment income, capital income (dividends and capital gains), income transfers (e.g., child allowance), and social security benefits (e.g., parental leave benefits). Social security benefits are often linked to previous earnings, typically earnings during the past 1-2 years. Annual earnings were also measured as the logarithm of the average of annual 
Depressive symptoms and income

wage and salary earnings over the period of 1993-2010. Both of these measures were deflated using the consumer price index (base year 2000).

\section{Statistical Analyses}

Linear regression analyses were used to examine the relationship between depressive symptoms and income and earnings. Four different models were used to examine whether confounders or mediators explained the examined association. In model 1, all analyses were adjusted for age and cohort. In model 2, additional adjustments were done for childhood parental SES. In model 3, participants' education was adjusted for. In model 4 , history of unemployment was additionally adjusted for, and in model 5 additional adjustments were done for health behaviors (smoking and alcohol consumption) Finally, in model 5, additional adjustment for three major temperament traits were done. All analyses were conducted separately for men and women.

\section{RESULTS}

Descriptive statistics are shown in Table 1. When compared to the original participants, current study participants were more likely to be women ( $53 \%$ vs. $48 \%$, p<.001), younger ( $\mathrm{p}<.001)$, and have higher parental SES $(\mathrm{p}<.01)$. Interaction analyses showed that the association between depressive symptoms with income and earnings differed between men and women (for income: interaction term regression coefficient $=-.23 ; \mathrm{p}<.001$; for earnings: interaction term regression coefficient $=-.24 ; \mathrm{p}<.01)$.

The main results are shown in Table 2. Higher depressive symptoms were associated with lower total income and earnings for women and men. For women, the association between depressive symptoms and income, however, attenuated to statistically non-significant after 
adjustment for parental SES and participants' own education. Similarly, for women the association between depressive symptoms and earnings did not remain statistically significant in the model where history of unemployment was added. For men, the associations between depressive symptoms with income and earnings remained statistically significant after all additional adjustments. However, after adjustment for temperament traits, the association between depressive symptoms with income and earnings was attenuated $32 \%$ and $39 \%$, respectively.

Additional sensitivity analyses suggested that the association between depressive symptoms with income was stronger among younger participants (in women: three youngest cohorts, $\mathrm{B}=-0.09, \mathrm{SE}=0.05, \mathrm{p}=0.04$ vs. three oldest cohorts, $\mathrm{B}=-0.05, \mathrm{SE}=0.05, \mathrm{p}=0.34$; in men: three youngest cohorts, $\mathrm{B}=-0.38, \mathrm{SE}=0.07, \mathrm{p}<0.01$ vs. three oldest cohorts, $\mathrm{B}=-0.23, \mathrm{SE}=0.05$, $\mathrm{p}<0.01)$. In addition, when participants who were in the highest $10 \%$ of depressive symptoms were excluded, the association between depressive symptoms with income attenuated in women $(\mathrm{B}=-0.02, \mathrm{SE}=0.03, \mathrm{p}=0.43)$ and in men $(\mathrm{B}=-0.19, \mathrm{SE}=0.04, \mathrm{p}<0.01)$.

\section{DISCUSSION}

Using a prospective cohort data in which annual income and earnings were followed over 17 years, the results showed that higher depressive symptoms are associated with lower future annual income and earnings. However, these associations were stronger for younger participants and around three times stronger for men, which is one novel finding of the current study, whose average annual income became $22 \%$ lower per one point increase in depressive symptoms mean score. Current study findings, which are based on accurate administrative income and earnings 
measures, highlight the importance of depressive symptoms in adolescence and early adulthood as a determinant of income prospects later in life.

There are number of reasons why depressive symptoms could lower future income. Depression in adolescence and early adulthood has been shown to predict dropping-out from higher education (Kessler and Bromet, 2013). Depressive symptoms are also associated with sickness absence (Bültmann et al., 2006) and work disability (Ahola et al., 2011) both of which are likely to lead to lower long-term income. In addition, people with depressive symptoms also perform less efficiently in their jobs (Lerner and Henke, 2008), which may reduce earnings, particularly if earnings are based on performance ratings at work.

The reasons for the finding that the association between depressive symptoms and earnings was considerably stronger among men remain unclear. Men have been shown to be less likely to seek help for their mental health problems (Oliver et al., 2005), which can lead, for example, to prolonged depressive episodes or early work disability. Men also have narrower social networks, and thus depressive symptoms might lead to the erosion of these networks that in turn could lead to difficulties in finding well-paid jobs.

From the number of examined confounders or mediators (i.e., parental SES, history of unemployment, health behaviors), only temperament traits reduced the strength of the associations. The power of temperament in explaining the association between depressive symptoms and income is understandable, as number of major temperament (i.e., personality) traits have been associated with both income (Viinikainen et al., 2010) and depressive symptoms (Hakulinen et al., 2015). However, controlling for temperament could also result to overadjustment as, for example, negative emotionality and depressive symptoms are partly overlapping constructs that have bidirectional relationship (Hakulinen et al., 2015). 
The main strengths of the current study are the nationally fairly representative sample, prospective research design and accurate long-term administrative measures of income and earnings. The main limitations of the study are attrition, which was partly selective, and that some participants were in their 30s when their depressive symptoms were measured and thus previous depressive episodes might already have had some influence on their economic and educational choices.

To conclude, the results show that depressive symptoms in adolescence and early adulthood lower future earnings especially among men. These findings highlight the importance of providing treatment for individuals with depressive symptoms or sub-threshold depression.

\section{REFERENCES}

Ahola, K., Virtanen, M., Honkonen, T., Isometsä, E., Aromaa, A., Lönnqvist, J., 2011. Common mental disorders and subsequent work disability: A population-based Health 2000 Study. J. Affect. Disord. 134, 365-372.

Bültmann, U., Rugulies, R., Lund, T., Christensen, K.B., Labriola, M., Burr, H., 2006. Depressive symptoms and the risk of long-term sickness absence: A prospective study among 4747 employees in Denmark. Soc. Psychiatry Psychiatr. Epidemiol. 41, 875-880.

Elovainio, M., Jokela, M., Rosenström, T., Pulkki-Råbäck, L., Hakulinen, C., Josefsson, K., Hintsanen, M., Hintsa, T., Raitakari, O.T., Keltikangas-Järvinen, L., 2014. Temperament and depressive symptoms: What is the direction of the association? J. Affect. Disord. 170C, $203-212$.

Elovainio, M., Pulkki-Råback, L., Jokela, M., Kivimäki, M., Hintsanen, M., Hintsa, T., Viikari, J., Raitakari, O.T., Keltikangas-Järvinen, L., 2012. Socioeconomic status and the 
development of depressive symptoms from childhood to adulthood: A longitudinal analysis across 27 years of follow-up in the Young Finns study. Soc. Sci. Med. 74, 923-929.

Ferrari, A.J., Charlson, F.J., Norman, R.E., Patten, S.B., Freedman, G., Murray, C.J.L., Vos, T., Whiteford, H.A., 2013. Burden of Depressive Disorders by Country, Sex, Age, and Year: Findings from the Global Burden of Disease Study 2010. PLoS Med. 10.

Hakulinen, C., Elovainio, M., Pulkki-Råback, L., Virtanen, M., Kivimäki, M., Jokela, M., 2015. Personality and Depressive Symptoms: Individual Participant Meta-Analysis of 10 Cohort Studies. Depress. Anxiety 32, 461-470.

Katainen, S., Räikkönen, K., Keltikangas- Järvinen, L., 1999. Adolescent temperament, perceived social support, and depressive tendencies as predictors of depressive tendencies in young adulthood. Eur. J. Pers. 13, 183-207.

Kessler, R.C., Bromet, E.J., 2013. The Epidemiology of Depression Across Cultures. Annu. Rev. Public Health 34, 119-138.

Lerner, D., Henke, R.M., 2008. What does research tell us about depression, job performance, and work productivity? J. Occup. Environ. Med. 50, 401-410.

Lorant, V., 2003. Socioeconomic Inequalities in Depression: A Meta-Analysis. Am. J. Epidemiol. 157, 98-112.

Oliver, M.I., Pearson, N., Coe, N., Gunnell, D., 2005. Help-seeking behaviour in men and women with common mental health problems: cross-sectional study. Br. J. Psychiatry 186, $297-301$.

Pehkonen, J., Viinikainen, J., Böckerman, P., Pulkki-Råback, L., Keltikangas-Järvinen, L., Raitakari, O., 2015. Relative age at school entry, school performance and long-term labour market outcomes. Appl. Econ. Lett. 22, 1345-1348. 
Pulkki, L., Keltikangas-Järvinen, L., Ravaja, N., Viikari, J., 2003. Child-rearing attitudes and cardiovascular risk among children: moderating influence of parental socioeconomic status. Prev. Med. (Baltim). 36, 55-63.

Raitakari, O.T., Juonala, M., Rönnemaa, T., Keltikangas-Järvinen, L., Räsänen, L., Pietikäinen, M., Hutri-Kähönen, N., Taittonen, L., Jokinen, E., Marniemi, J., Jula, A., Telama, R., Kähonen, M., Lehtimäki, T., Åkerblom, H.K., Viikari, J.S. a, Kähönen, M., Lehtimäki, T., Akerblom, H.K., Viikari, J.S. a, 2008. Cohort profile: the cardiovascular risk in Young Finns Study. Int. J. Epidemiol. 37, 1220-6.

Rosenström, T., Jokela, M., Puttonen, S., Hintsanen, M., Pulkki-Råback, L., Viikari, J.S., Raitakari, O.T., Keltikangas-Järvinen, L., 2012. Pairwise measures of causal direction in the epidemiology of sleep problems and depression. PLoS One 7, e50841.

Viinikainen, J., Kokko, K., Pulkkinen, L., Pehkonen, J., 2010. Personality and Labour Market Income: Evidence from Longitudinal Data. Labour 24, 201-220.

Whooley, M., Kiefe, C., Chesney, M., Markovitz, J., Matthews, K., Hulley, S., 2002. Depressive Symptoms, Unemployment, and Loss of Income. Arch. Intern. Med. 162, 2614-2620.

Zimmerman, F.J., Katon, W., 2005. Socioeconomic status, depression disparities, and financial strain: What lies behind the income-depression relationship? Health Econ. 14, 1197-1215.

Table 1. Descriptive statistics of the study sample

\begin{tabular}{lllll}
\hline & \multicolumn{2}{l}{ Women $(\mathrm{n}=971)$} & \multicolumn{2}{c}{ Men $(\mathrm{n}=738)$} \\
& Mean (or \%) & SD & Mean (or \%) & SD \\
\hline Age in 1992 & 22.18 & 4.93 & 21.92 & 5.09 \\
Measures from 1980 & & & & \\
& & & &
\end{tabular}


Depressive symptoms and income

Parental SES

0.06

1.70

0.22

1.64

Measures from 1992

Depressive symptoms

2.21

0.63

2.03

0.56

History of unemployment (yes)

$28 \%$

$37 \%$

Currently smoking (yes)

$22 \%$

$32 \%$

Alcohol consumption (high)

$5 \%$

$9 \%$

Activity

2.97

0.56

2.87

0.54

Sociability

3.97

0.71

3.71

0.70

Negative Emotionality

2.66

0.63

2.37

0.61

Measures obtained from FLEED

Obtained tertiary education

$33.78 \%$

$29.81 \%$

Average annual income ${ }^{1}$ from 1993 to 2010

$15555 €$

$21388 €$

$16496 €$

Average annual earnings ${ }^{2}$ from 1993 to 2010

$13322 €$

$7540 € \quad 19042 €$

$10591 €$

\footnotetext{
${ }^{\mathrm{I}}$ Average annual income includes annual wage and salary earnings, self-employment income, capital income, income transfers, and social security benefits

${ }^{2}$ Average annual earnings includes annual wage and salary earnings
}

Table 2. Association between depressive symptoms with average annual income and earnings

\begin{tabular}{lllllll}
\hline Women $(\mathrm{n}=$ 971) & Income & \multicolumn{5}{c}{ Earnings } \\
& B & SE & $\mathrm{p}$ & $\mathrm{B}$ & $\mathrm{SE}$ & $\mathrm{p}$ \\
\hline Model 1 & -0.07 & 0.03 & $\mathbf{0 . 0 4}$ & -0.13 & 0.05 & $\mathbf{0 . 0 1}$ \\
Model 2 & -0.07 & 0.03 & 0.05 & -0.13 & 0.06 & $\mathbf{0 . 0 2}$ \\
Model 3 & -0.06 & 0.03 & 0.09 & -0.11 & 0.05 & $\mathbf{0 . 0 4}$
\end{tabular}


Depressive symptoms and income

\begin{tabular}{lllllll} 
Model 4 & -0.05 & 0.03 & 0.11 & -0.10 & 0.05 & 0.05 \\
Model 5 & -0.05 & 0.03 & 0.11 & -0.10 & 0.05 & 0.05 \\
Model 6 & -0.08 & 0.05 & 0.13 & -0.15 & 0.09 & 0.10 \\
\hline Men (n = 738) & $\mathrm{B}$ & $\mathrm{SE}$ & $\mathrm{p}$ & $\mathrm{B}$ & $\mathrm{SE}$ & $\mathrm{p}$ \\
\hline Model 1 & -0.30 & 0.05 & $<\mathbf{0 . 0 1}$ & -0.38 & 0.06 & $<\mathbf{0 . 0 1}$ \\
Model 2 & -0.30 & 0.05 & $<\mathbf{0 . 0 1}$ & -0.38 & 0.06 & $<\mathbf{0 . 0 1}$ \\
Model 3 & -0.29 & 0.04 & $<\mathbf{0 . 0 1}$ & -0.36 & 0.06 & $<\mathbf{0 . 0 1}$ \\
Model 4 & -0.28 & 0.04 & $\mathbf{< 0 . 0 1}$ & -0.35 & 0.06 & $<\mathbf{0 . 0 1}$ \\
Model 5 & -0.27 & 0.04 & $<\mathbf{0 . 0 1}$ & -0.34 & 0.06 & $<\mathbf{0 . 0 1}$ \\
Model 6 & -0.18 & 0.07 & $<\mathbf{0 . 0 1}$ & -0.21 & 0.09 & $\mathbf{0 . 0 2}$ \\
\hline
\end{tabular}

Values are regression coefficients (B), standard errors (SE), and p-values (p).

Model 1: Adjusted for age and cohort

Model 2: Adjusted for age, cohort, and parental SES

Model 3: Adjusted for age, cohort, parental SES, and education

Model 4: Adjusted for age, cohort, parental SES, education, and history of unemployment

Model 5: Adjusted for age, cohort, parental SES, education, history of unemployment, and health behaviors

Model 6: Adjusted for age, cohort, parental SES, education, history of unemployment, health behaviors, and temperament traits

\section{Highlights}

- A nationally fairly representative sample of Finns whose annual register based income details were followed over 17 years was used. 
- Higher depressive symptoms in adolescence and early adulthood predict lower future annual income and earnings.

- These associations are particularly strong for men. 